2nd International Conference on Ultrafine Grained \&

Nanostructured Materials (UFGNSM)

International Journal of Modern Physics: Conference Series

Vol. 5 (2012) 784-792

(C) World Scientific Publishing Company

DOI: $10.1142 / \mathrm{S} 2010194512002759$

\title{
THE EFFECT OF ACTIVE SCREEN PLASMA NITRIDING TREATMENT ON STRUCTURAL, MECHANICAL AND MAGNETIC PROPERTIES OF NANOCRYSTALLINE FINEMET-TYPE ALLOY
}

\author{
E. MEMARZADEH LOTFABAD \\ Department of Materials Science and Engineering, Sharif University of Technology, Azadi Ave, \\ Tehran, P. O. Box 11365-9466, 1458889694, Iran \\ e.memarzadeh@yahoo.com \\ H. R. MADAAH HOSSEINI \\ Department of Materials Science and Engineering, Sharif University of Technology, Azadi Ave, \\ Tehran, P. O. Box 11365-9466, 1458889694, Iran \\ madaah@sharif.edu
}

\begin{abstract}
The Active Screen Plasma Nitriding (ASPN) treatment of $\mathrm{Fe}_{73.5} \mathrm{Si}_{13.5} \mathrm{~B}_{9} \mathrm{Nb}_{3} \mathrm{Cu}_{1}$ alloy was investigated for $3 \mathrm{~h}$ at $480{ }^{\circ} \mathrm{C}$ and $560{ }^{\circ} \mathrm{C}$ in various $\mathrm{N}_{2}-\mathrm{H}_{2}$ gas mixtures at 5 mbar atmosphere. The amorphous ribbons were then annealed under vacuum at the same time and temperatures. The samples were characterized by X-ray Diffraction (XRD), Scanning Electron Microscopy (SEM), Microhardness measurements and Vibrating Sample Magnetometer (VSM). It was observed that the ASPN treatment leads to finer grain size and higher crystalline volume fraction and modifies the structural features of $\mathrm{Fe}(\mathrm{Si})$ phase. The $\mathrm{Fe}(\mathrm{Si})$ lattice parameter for the nitrided samples was higher than that for the annealed samples due to the diffusion of nitrogen into the $\mathrm{Fe}(\mathrm{Si})$ phase and the formation of $\mathrm{Si}-\mathrm{N}$ precipitates. In ASPN treatment, the lowest magnitude of coercivity and the maximum saturated magnetization were obtained at $480{ }^{\circ} \mathrm{C}$ and $560{ }^{\circ} \mathrm{C}$, respectively, in $75 \% \mathrm{H}_{2}-25 \% \mathrm{~N}_{2}$ gas mixture. ASPN treatment increased the microhardness of the samples.
\end{abstract}

Keywords: Finemet alloy; nanocrystallization; active screen plasma nitriding.

\section{Introduction}

Investigations on nanocrystalline materials started back in 1988 where Yoshizawa, Oguma and Jamauchi were the first researchers to obtain a nanocrystalline material from a metallic glass. ${ }^{1}$ The nanocrystalline Finemet type alloys obtained by controlled crystallization of the amorphous samples due to their excellent soft magnetic properties, are very attractive for application. The formation of $\mathrm{Cu}$-rich clusters as nucleation sites before crystallization, and the grain growth inhibiting effect of $\mathrm{Nb}$ atoms, lead to the formation of a nano-scale microstructure ${ }^{2,3}$, which improves magnetic softness of the alloy according to random anisotropy model. ${ }^{4,5}$ In addition, the method and condition of nanocrystallization treatment play an important role on the resulted nanostructure. ${ }^{6}$ Commonly, classical thermal treatments under vacuum are used. The Gas Nitriding (GN) 
treatment is a suitable surface treatment process which enhances the hardness, wear and corrosion resistance of steels. ${ }^{7}$ This kind of treatment improves nanocrystalline state by decreasing the $\mathrm{Fe}(\mathrm{Si})$ grain size and increasing the crystalline fraction as already reported by Atmani et al. ${ }^{6}$ It has been found that higher parameters of crystallization $\left(520{ }^{\circ} \mathrm{C}\right.$ and 6 h) than those commonly used in the conventional treatment $\left(500{ }^{\circ} \mathrm{C}\right.$ and $\left.1 \mathrm{~h}\right)$ result in significantly higher coercivity for the GN treated samples.

Plasma nitriding process is widely used and has a number of distinct advantages over gas nitriding such as greater economy of gases, minor process duration, since the nitrogen diffusion speed is greater. ${ }^{8}$ Furthermore, it can be applied in lower temperatures due to plasma activation. However, in conventional plasma nitriding, the components to be treated are subject to a high cathodic potential. This may bring some inherent shortcomings such as damage caused to the parts by arcing, the edging effect, hollow cathode effect and difficulty in maintaining a uniform chamber temperature, especially in thin ribbon samples. ${ }^{9}$ In order to reduce the effects of the above-mentioned disadvantages some new processes were developed including postdischarge nitriding such as Active Screen Plasma Nitriding (ASPN) technology. In such a novel nitriding process, the entire workload is surrounded by a large metal screen, on which a high voltage cathodic potential is applied. The worktable and the components to be treated are insulated from the cathodic screen and the anodic chamber walls., 9

This study aims to characterize the influence of the ASPN treatment on the crystallization process of $\mathrm{Fe}_{73.5} \mathrm{Si}_{13.5} \mathrm{~B}_{9} \mathrm{Nb}_{3} \mathrm{Cu}_{1}$ amorphous alloy. The structural, mechanical and magnetic properties of the nitrided alloy are investigated and compared with those of the same alloy annealed under vacuum and gas nitrided.

\section{Experimental Procedure}

Ingot of master alloys were prepared by arc melting under protective atmosphere and the actual composition was determined by inductively coupled plasma (ICP) analysis. Amorphous ribbons were prepared by single roller melt spinning method with the cross section of $0.02 \times 1.00 \mathrm{~mm}$. The ASPN treatment was carried out in a $6.5 \mathrm{KW}$ conventional DC plasma nitriding unit. The amorphous ribbons were subjected to the ASPN treatment at $480{ }^{\circ} \mathrm{C}$ and $560{ }^{\circ} \mathrm{C}$ for $3 \mathrm{~h}$ and in two gas mixtures of $75 \% \mathrm{~N}_{2}-25 \% \mathrm{H}_{2}$ and $75 \% \mathrm{H}_{2}-$ $25 \% \mathrm{~N}_{2}$. The chamber pressure was $5 \pm 1$ mbar. The amorphous ribbons were mounted on the stainless steel fixture and placed in the active screen setup, which was put directly on the electrically insulated stage (cathode) of the plasma nitriding unit. The chamber was served as anode. In order to compare conventional annealing with ASPN treatment, the amorphous ribbons were encapsulated in a quartz tube under vacuum and placed in a furnace under the same conditions of temperatures and time. The Structural changes of the ribbons was analyzed using X-ray diffraction with $\mathrm{Cu} \mathrm{K}_{\alpha}$ radiation $(\lambda=1.54056 \AA)$ in a Philips PW 1800 diffractometer. Tscan Vega2 Scanning Electron Microscopy (SEM) with energy dispersive spectroscopy (EDS) was employed for the qualitative composition analyses and elements distribution from surface to center of the ribbons. The 
microhardness test with a load of $50 \mathrm{~g}$ was carried out. The magnetic properties were measured at room temperature using Vibrating Sample Magnetometer (VSM).

\section{Results and Discussion}

\section{1. $X R D$ results}

The XRD patterns of the nitrided and annealed samples are presented in Fig.1 which exhibit three major diffraction lines corresponding to the $\left(\begin{array}{lll}1 & 1 & 0\end{array}\right),\left(\begin{array}{lll}2 & 0 & 0\end{array}\right)$ and $\left(\begin{array}{lll}2 & 1 & 1\end{array}\right)$ reflections of the $\alpha-\mathrm{Fe}(\mathrm{Si})$ phase.

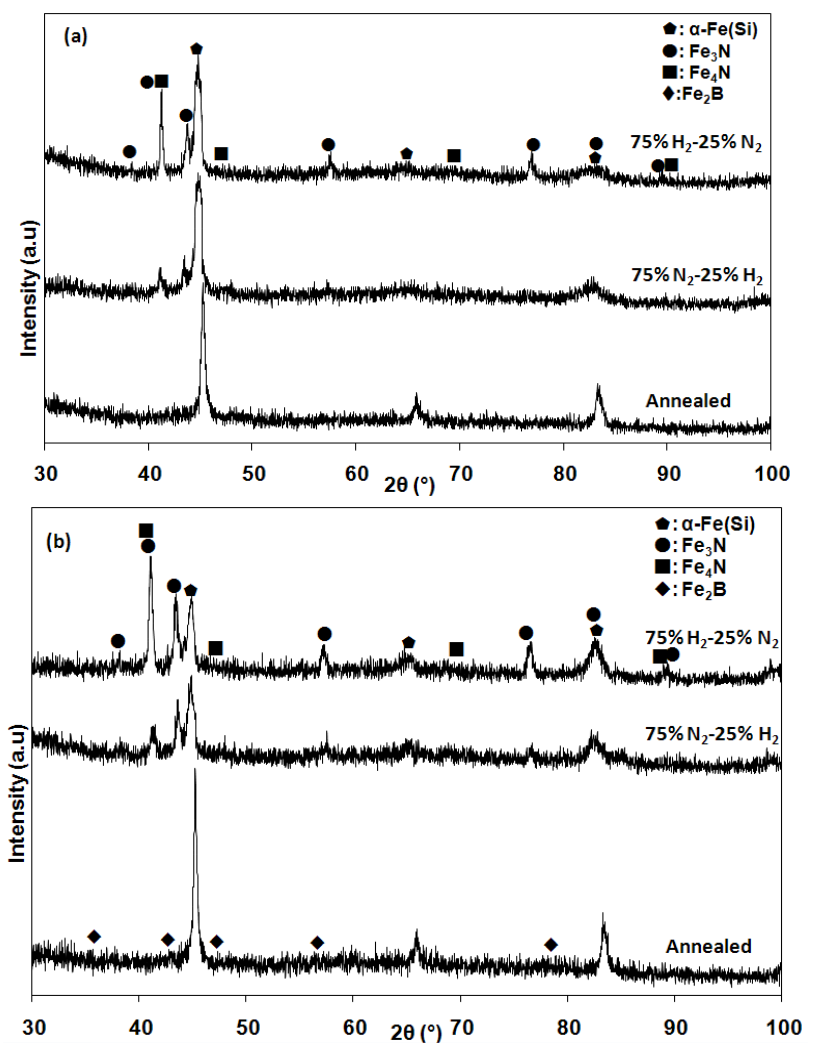

Fig. 1. XRD patterns of the nitrided and annealed ribbons at (a) $480{ }^{\circ} \mathrm{C}$ and (b) $560{ }^{\circ} \mathrm{C}$ for $3 \mathrm{~h}$.

As shown, heat treatment at $480{ }^{\circ} \mathrm{C}$ causes nanocrystallization of the amorphous matrix for all samples and the formation of the iron nitrides such as $\mathrm{Fe}_{4} \mathrm{~N}$ and $\mathrm{Fe}_{2-3} \mathrm{~N}$ phases for the nitrided samples. At this temperature, the intensity of $\mathrm{Fe}(\mathrm{Si})$ phase in the nitrided samples was somewhat similar to that in the annealed samples, indicating that a very thin compound layer formed, the atomic nitrogen diffused into the $\mathrm{Fe}(\mathrm{Si})$ phase. So $\alpha-\mathrm{Fe}$ and $\mathrm{Si}-\mathrm{N}$ formed due to a reaction between $\mathrm{N}$ and $\mathrm{Si}$. As the nitrogenation reaction proceeds, $\mathrm{Fe}_{4} \mathrm{~N}$ forms according to the following reaction ${ }^{11}$ : 


$$
4 \mathrm{Fe}+\mathrm{N} \rightarrow \mathrm{Fe}_{4} \mathrm{~N}
$$

The presence of Si nitrides is not to be completely excluded. However, the techniques used did not allow such nitrides to be identified because of their small size together with their slight quantities. The superlattice diffraction peaks of $\mathrm{Fe}_{3} \mathrm{Si}$ phase were weak and they could not be seen at all in the x-ray diffractometry done here. At $560{ }^{\circ} \mathrm{C}$, unlike the annealed samples, the intensity of the $\mathrm{Fe}(\mathrm{Si})$ peaks for the nitrided samples reduced by increasing of the compound layer thickness. The thicker compound layers prevent the incident X-rays from reaching the ferritic substrate. ${ }^{12}$ The disappearance of the boride phases in the nitrided samples at $560{ }^{\circ} \mathrm{C}$ could be due to a nitrogenation reaction, in relation with the formation of $\mathrm{Fe}_{4} \mathrm{~N}{ }^{11}$

It should be noted that the compound layer on the surface of the screen contains more $\mathrm{Fe}_{2-3} \mathrm{~N}$ phase at all temperatures with increasing of the nitrogen in the gas mixture. ${ }^{10}$ Accordingly, the sputtered particles from the screen and those deposited on the surface of the ribbons had more nitrogen content than those in $75 \% \mathrm{H}_{2}-25 \% \mathrm{~N}_{2}$ gas mixture. It could be concluded that according to the exponential law distribution for the nitrogen, in $75 \%$ $\mathrm{N}_{2}-25 \% \mathrm{H}_{2}$ gas mixture, nitrogen concentration at a specific distance from the surface is more than that in $75 \% \mathrm{H}_{2}-25 \% \mathrm{~N}_{2}$, as follows ${ }^{13}$ :

$$
C(x, t)=C_{s}\left(1-\operatorname{erf} x / 2 \sqrt{t D_{N}}\right)
$$

Where, $x$ is the distance from the surface, $t$ is the time, $D_{N}$ is the total nitrogen diffusion coefficient and $C_{s}$ is the nitrogen concentration in the surface of the nitrided samples. Since the hydrogen ionization needs lower energy and ionizes faster than nitrogen, so the additional hydrogen up to $75 \%$ might facilitate the iron nitrides sputtering on the screen, resulting in thicker compound layer than in $75 \% \mathrm{~N}_{2}-25 \% \mathrm{H}_{2}$. Moreover, the compound layer contains more $\mathrm{Fe}_{4} \mathrm{~N}$ phase in $75 \% \mathrm{H}_{2}-25 \% \mathrm{~N}_{2}$ according to the XRD results.

The average crystallites size was calculated from the broadening of XRD peaks using Williamson and Hall procedure as well as the crystalline fraction embedded in the amorphous matrix for different heat treatment temperatures (Table 1).

For the nitrided samples, the crystalline volume fraction is higher than that for the annealed samples. By increasing of the heat treatment temperature for all samples, the crystalline volume fraction rises, but a different behavior in terms of grain size was observed at $560{ }^{\circ} \mathrm{C}$ for the nitrided and annealed samples. Despite the abrupt increase of grain size for the annealed samples, it has not altered significantly for the nitrided samples due to the $\mathrm{Si}$ ex-solution in the $\mathrm{Fe}(\mathrm{Si})$ phase and also formation of more $\mathrm{Si}-\mathrm{N}$ precipitates. As could be seen, the sequence of $\mathrm{Fe}(\mathrm{Si})$ grain size for the samples is as:

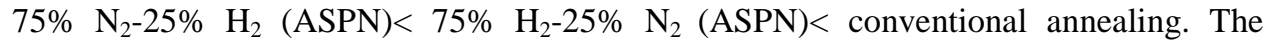
smaller grain size of the $\mathrm{Fe}(\mathrm{Si})$ crystallites in $75 \% \mathrm{~N}_{2}-25 \% \mathrm{H}_{2}$ is probably due to the diffusion of more nitrogen through the samples and the formation of more $\mathrm{Si}-\mathrm{N}$ precipitates. In addition, the higher crystalline volume fraction and also the smaller value of the grain diameter of the nitrided samples play an important role in the effective magnetosriction constant. ${ }^{6}$ 
Table 1. Grain size of the $\mathrm{Fe}(\mathrm{Si})$ phase and volume fraction of the crystalline phase

$$
\text { ASPN: } 75 \% \mathrm{~N}_{2}-25 \% \mathrm{H}_{2} \quad \text { ASPN: } 25 \% \mathrm{~N}_{2}-75 \% \mathrm{H}_{2} \quad \text { Annealed }
$$

\begin{tabular}{ccccccc}
\hline $\begin{array}{c}\text { Temperature } \\
\left({ }^{\circ} \mathrm{C}\right)\end{array}$ & $\begin{array}{c}\text { Grain size } \\
(\mathrm{nm})\end{array}$ & $\begin{array}{c}\text { Volume fraction } \\
(\%)\end{array}$ & $\begin{array}{c}\text { Grain size } \\
(\mathrm{nm})\end{array}$ & $\begin{array}{c}\text { Volume fraction } \\
(\%)\end{array}$ & $\begin{array}{c}\text { Grain size } \\
(\mathrm{nm})\end{array}$ & $\begin{array}{c}\text { Volume fraction } \\
(\%)\end{array}$ \\
\hline 480 & 8.2 & 79 & 9.8 & 77 & 11.5 & 71 \\
\hline 560 & 10 & 89 & 11 & 88 & 22 & 85 \\
\hline
\end{tabular}

The lattice parameter $\alpha$ of the BCC $\alpha-\mathrm{Fe}(\mathrm{Si})$ phase, measured for both samples, and the corresponding Si content (estimated from Ref. 14) are presented in Table 2. But this calculation is not possible for the nitrided ribbons, where the lattice parameter may also be modified by the presence of nitrogen in the structure. ${ }^{15}$ The lattice parameter of a part of the $\alpha-\mathrm{Fe}(\mathrm{Si})$ crystallites where nitrogen has diffused, is larger in the nitrided samples compared to the annealed samples due to the diffusion and solution of nitrogen and also formation of $\mathrm{Si}-\mathrm{N}$ precipitates. It increases at $560{ }^{\circ} \mathrm{C}$ due to $\mathrm{Si}$ ex-solution in the $\alpha-\mathrm{Fe}(\mathrm{Si})$ phase. The superior nitriding potential, the larger lattice parameter of the $\alpha-\mathrm{Fe}(\mathrm{Si})$ phase .

Table 2. Lattice parameter $a$ of the a-Fe( $\mathrm{Si}$ ) phase and derived $\mathrm{Si}$ contentin the CTT samples $^{\mathrm{a}}$

\begin{tabular}{ccccccc} 
& ASPN: $75 \% \mathrm{~N}_{2}-25 \% \mathrm{H}_{2}$ & ASPN: $25 \%$ & $\mathrm{~N}_{2}-75 \% \mathrm{H}_{2}$ & \multicolumn{2}{c}{ Annealed } \\
\hline $\begin{array}{c}\text { Temperature } \\
\left({ }^{\circ} \mathrm{C}\right)\end{array}$ & $\mathrm{a}(\mathrm{nm})$ & at $\% \mathrm{Si}$ & $\mathrm{a}(\mathrm{nm})$ & at $\% \mathrm{Si}$ & $\mathrm{a} \mathrm{(nm)}$ & at $\% \mathrm{Si}$ \\
\hline 480 & 2.859 & - & 2.855 & - & 2.843 & 14.5 \\
\hline 560 & 2.867 & - & 2.866 & - & 2.852 & 10.5 \\
\hline
\end{tabular}

Estimated errors are: $\pm 0.002 \mathrm{~nm}$ for $a$ and $\pm 1 \%$ for at $\% \mathrm{Si}$.

\subsection{SEM results}

To know whether nitrided phases were coated on the surface and diffused into the ribbons, the concentration of alloying elements containing nitrogen were analyzed along the thickness direction using EDS (Fig. 2). As can be seen, EDS analysis shows the presence of $\mathrm{Fe}$ and $\mathrm{N}$ on the surface of the ribbons which is generally referred to the compound layer. It shows a weak $\mathrm{Si}$ peak from the surface of the ribbons. But, It is demonstrated the presence of $\mathrm{Fe}, \mathrm{Si}$ and a slight amount of $\mathrm{N}$ in the center of the ribbons. The concentration of nitrogen in the compound layer is more than that of the diffusion zone. Moreover, the nitrogen content on the surface of the ribbons is higher in $75 \% \mathrm{~N}_{2^{-}}$ $25 \% \mathrm{H}_{2}$ gas mixture than in $75 \% \mathrm{H}_{2}-25 \% \mathrm{~N}_{2}$ in which, it contains more $\mathrm{Fe}_{2-3} \mathrm{~N}$ phase than $\mathrm{Fe}_{4} \mathrm{~N}$ according to the $\mathrm{XRD}$ results. What is more, the nitrogen concentration in the center of the ribbons increases with the increasing of the nitrogen content in the gas mixture. 


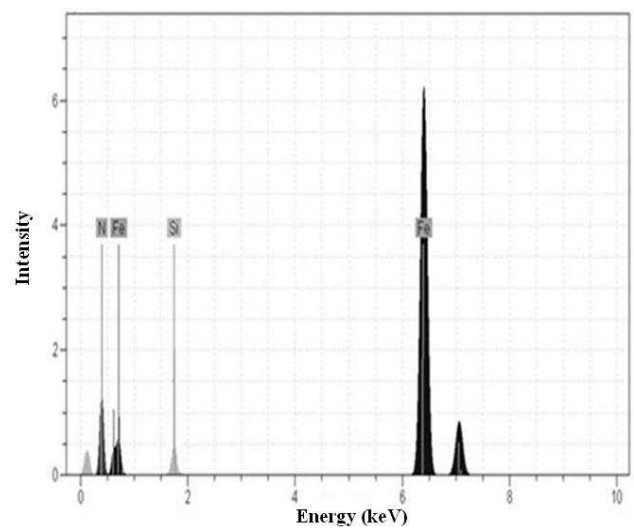

(a)

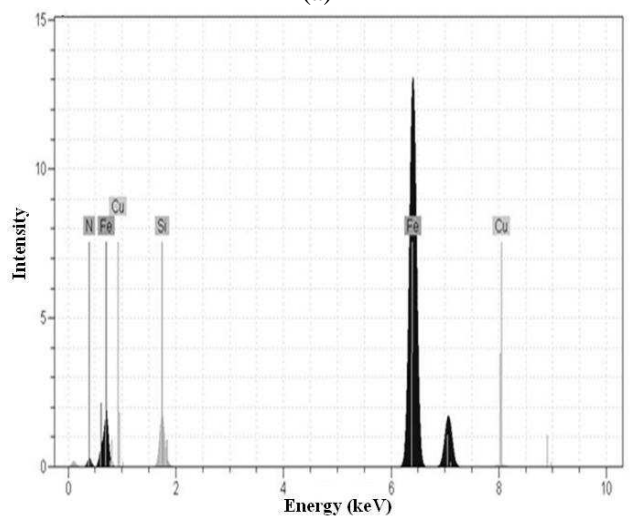

(c)

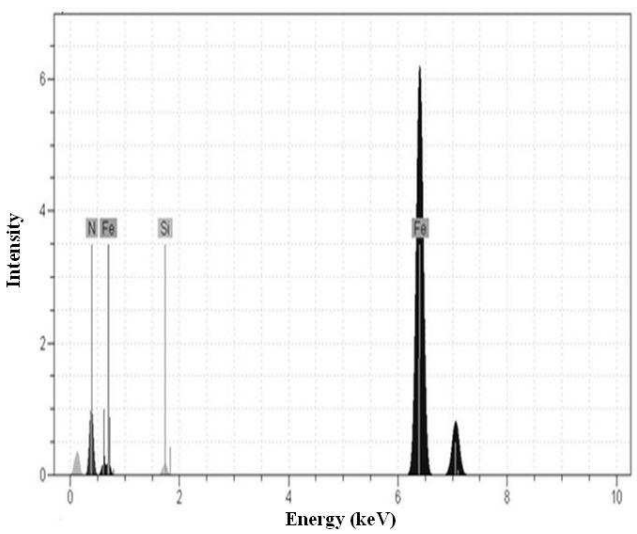

(b)

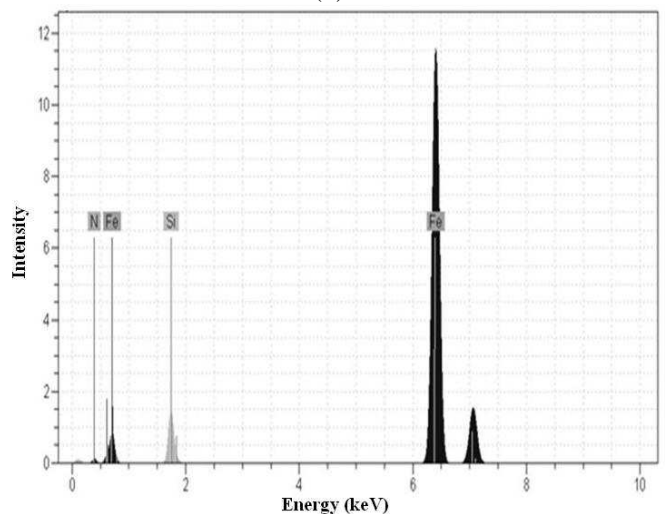

(d)

Fig. 2. EDS analysis from the surface (a, b) and center (c, d) of the nitrided ribbons in $75 \% \mathrm{~N}_{2}-25 \% \mathrm{H}_{2}(\mathrm{a}, \mathrm{c})$ and $75 \%$ $\mathrm{H}_{2}-25 \% \mathrm{~N}_{2}(\mathrm{~b}, \mathrm{~d})$ gas mixture at $480{ }^{\circ} \mathrm{C}$.

\subsection{Microhardness results}

The results of Vickers microhardness measurements in the bulk of the ribbons as a function of treatment temperature are reported in Table 3. As could be seen, for the annealed samples, hardness increases due to the nanocrystallization process and the formation of the $\mathrm{Fe}(\mathrm{Si})$ phase. A slight decrease of the hardness values for the annealed samples at $560{ }^{\circ} \mathrm{C}$, could be seen which is due to the $\mathrm{Fe}(\mathrm{Si})$ grain growth. For the nitrided samples, increase in hardness at $480{ }^{\circ} \mathrm{C}$ is due to the same reasons for the annealed samples and also the diffusion of nitrogen into the ribbons as well as the formation of nitided phases that have high hardness. At $560^{\circ} \mathrm{C}$, the variation of the microhardness towards high values is linked to the high nitrogen concentration and nitrided phases in the bulk of the samples. According to the XRD results, the more nitrogen diffusion through the samples and the more nitrogen concentration lead to the higher values of hardness in $75 \% \mathrm{~N}_{2}-25 \% \mathrm{H}_{2}$ gas mixture than in $75 \% \mathrm{H}_{2}-25 \% \mathrm{~N}_{2}$. 
Table 3. Bulk microhardness versus temperature.

\begin{tabular}{ccc}
\cline { 2 - 3 } & Temperature $\left({ }^{\circ} \mathrm{C}\right)$ & Microhardness (HV) \\
\hline As-Spun & 27 & 910 \\
\hline \multirow{2}{*}{ ASPN: $75 \% \mathrm{~N}_{2}-25 \% \mathrm{H}_{2}$} & 480 & 1300 \\
\cline { 2 - 3 } & 560 & 1402 \\
\hline \multirow{2}{*}{ ASPN: $25 \% \mathrm{~N}_{2}-75 \% \mathrm{H}_{2}$} & 480 & 1289 \\
\cline { 2 - 3 } & 560 & 1390 \\
\hline \multirow{2}{*}{ Annealed } & 480 & 1270 \\
\cline { 2 - 3 } & 560 & 1258 \\
\hline
\end{tabular}

\subsection{Magnetic results}

In order to evaluate influences of nitriding and annealing on the magnetic properties of both samples, the room temperature hysteresis loops were measured (Fig. 3). It clearly shows that the nitrided samples exhibit a higher saturation magnetization than the annealed samples. Iron nitrides such as $\mathrm{Fe}_{4} \mathrm{~N}, \mathrm{Fe}_{2-3} \mathrm{~N}$ are attractive materials because they have high saturation magnetization. ${ }^{16}$ By increase of temperature, iron nitrides reach a saturated state mainly in the form of bigger average diameters. According to XRD results, the formation of more $\mathrm{Fe}_{4} \mathrm{~N}$ phase leads to the higher saturation magnetization in $75 \%$ $\mathrm{H}_{2}-25 \% \mathrm{~N}_{2}$ gas mixture. So the maximum saturated magnetization is obtained at $560{ }^{\circ} \mathrm{C}$ in $75 \% \mathrm{H}_{2}-25 \% \mathrm{~N}_{2}$ gas mixture.

According to Fig. 3, comparing the coercivity of the annealed samples with that obtained for the nitrided samples, it could be concluded that the coecivity is higher for the nitrided samples, but closer to the annealed samples compared to the GN treated samples ${ }^{6,11}, 15$, which is due to the lower nitrided layer thickness by optimizing the nitriding treatment. Moreover, the coercivity of the nitrided samples in this study is lower than that of the gas nitrided (GN) samples at $520{ }^{\circ} \mathrm{C}$ for $6 \mathrm{~h}$ from Refs. 6,11 and 15 due to using different temperatures and lower time in the ASPN treatment. However, the increase of coercivity compared with the annealed samples could be attributed to the formation of some iron nitrides such as $\mathrm{Fe}_{4} \mathrm{~N}$ and $\mathrm{Fe}_{2-3} \mathrm{~N}$, known as a "semi-hard" magnetic phases. ${ }^{6}$ Diffusion of nitrogen through the samples is higher in $75 \% \mathrm{~N}_{2}-25 \% \mathrm{H}_{2}$ gas mixture compared to $75 \% \mathrm{H}_{2}-25 \% \mathrm{~N}_{2}$ in agreement with XRD results. Accordingly, the coercivity is slightly higher in the gas mixture with the higher nitrogen potential at $480{ }^{\circ} \mathrm{C}$. Nitriding at $560{ }^{\circ} \mathrm{C}$ and the formation of significant thick nitrided layer considerably increase the coercivity but decreasing the grain size causes the less difference in coercivity of the nitrided samples with annealed samples compared to the results found for the gas nitriding treatment in Refs. 6,11 and 15. 


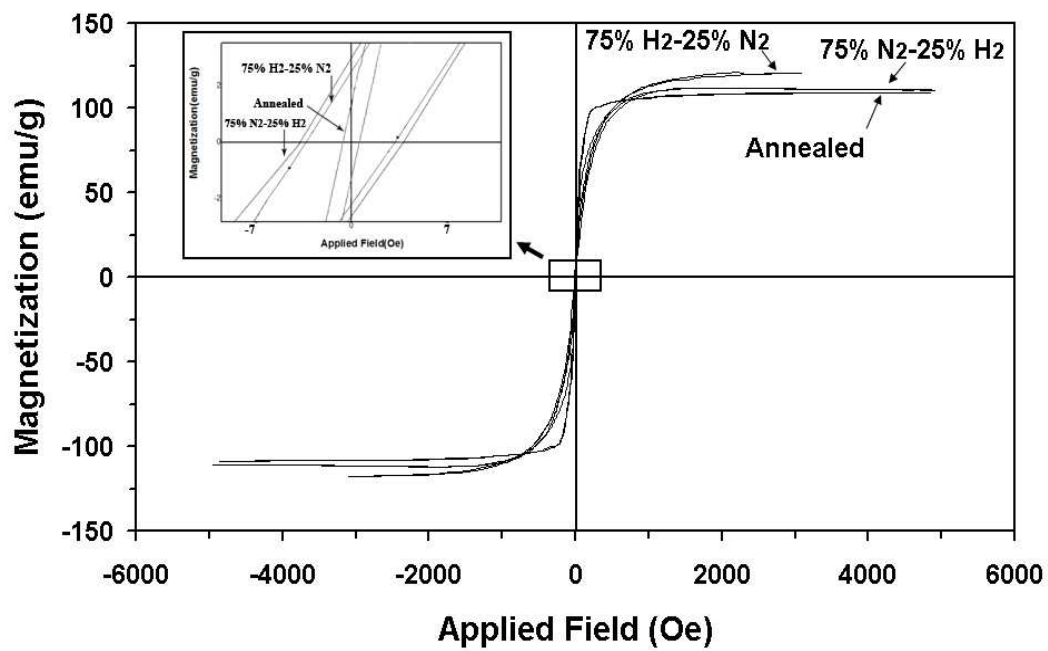

(a)

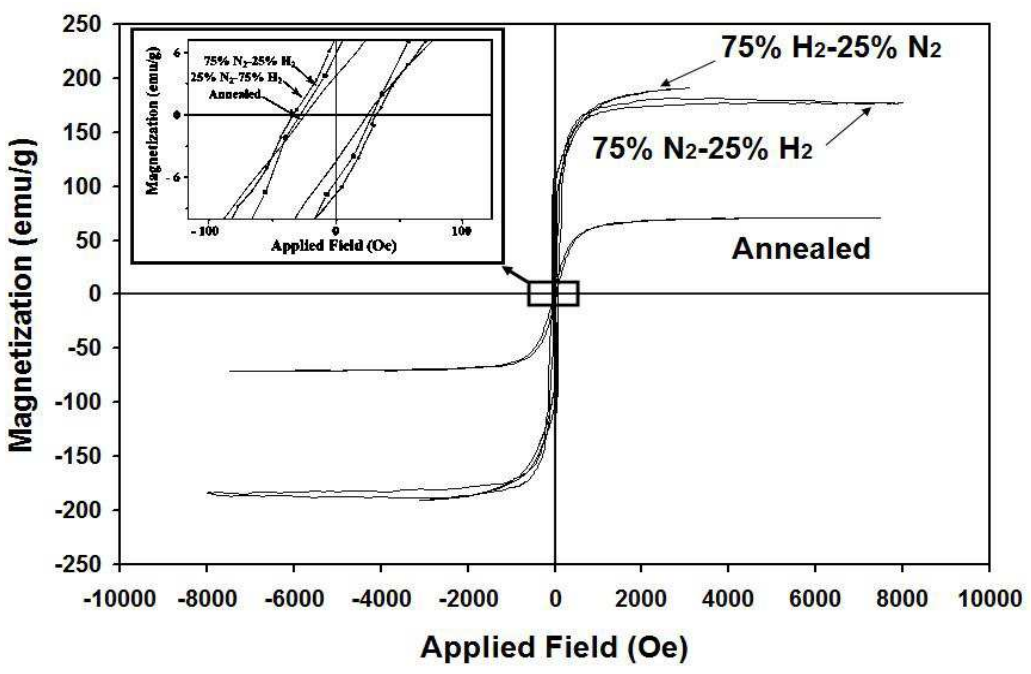

(b)

Fig. 3. Magnetization curve for different samples at (a), $480{ }^{\circ} \mathrm{C}$ and (b) $560{ }^{\circ} \mathrm{C}$.

\section{Conclusions}

In nitrided samples, the grain size of $\mathrm{Fe}(\mathrm{Si})$ phase decreased and the crystalline volume fraction increased, thus leading to a lower magnetostriction constant. Nitrogen seems to favor the appearance of crystalline $\alpha-\mathrm{Fe}(\mathrm{Si})$ regions with a low $\mathrm{Si}$ content, probably by forming a silicon nitride. The sequence of $\mathrm{Fe}(\mathrm{Si})$ grain size for the samples was as: $75 \%$ $\mathrm{N}_{2}-25 \% \mathrm{H}_{2}\left(\right.$ ASPN) $<75 \% \mathrm{H}_{2}-25 \% \mathrm{~N}_{2}($ ASPN) $<$ conventional annealing. The nitrogen content on the surface of the ribbons was higher in $75 \% \mathrm{~N}_{2}-25 \% \mathrm{H}_{2}$ gas mixture than in $75 \% \mathrm{H}_{2}-25 \% \mathrm{~N}_{2}$ in which, it contained more $\mathrm{Fe}_{2-3} \mathrm{~N}$ phase than $\mathrm{Fe}_{4} \mathrm{~N}$. Both magnetic and 
mechanical properties improved compared to the GN treatment by optimizing the nitrided layer thickness. In ASPN treatment, the lowest magnitude of coercivity and the maximum saturated magnetization were obtained at $480{ }^{\circ} \mathrm{C}$ and $560{ }^{\circ} \mathrm{C}$, respectively, in $75 \% \mathrm{H}_{2-}$ $25 \% \mathrm{~N}_{2}$ gas mixture.

\section{References}

1. T. Raszkaa and A. Przybył, "Optimisation of soft magnetic properties in $\mathrm{Fe}_{83-\mathrm{X}} \mathrm{Co}_{\mathrm{X}} \mathrm{Nb}_{3} \mathrm{~B}_{13} \mathrm{Cu}_{1}$ $(\mathrm{x}=10,30,40)$ amorphous alloys", Worldwide on Materials and Manufacturing Engineering and Technology, May 2005, pp. 535-538.

2. K. Hono, K. Hiraga, Q. Wang, A. Inoue, T. Sakman, Acta Metall. Mater. 40 (1992) 2137.

3. G. Herzer, in: K.H.J. Buschow (Eds.), Handbook of Magnetic Materials, vol. 10 (Elsevier, Amsterdam, 1997), pp. 415-462.

4. G. Herzer, IEEE Trans. Magn. 25, 3327 (1989).

5. A. Hernando, M. V'azquez, T. Kulik and C. Prados, Phys. Rev. B51, 3581 (1995).

6. H. Atmani, S. Grognet, J. Teillet, "Crystallization-nitriding process of $\mathrm{FeSiB}$ and $\mathrm{FeSiBCuNb}$ ribbons: influence of additive $(\mathrm{Cu}, \mathrm{Nb})$ pair and nitrogen on structure, magnetic and magnetostrictive parameters", Journal of Non-Crystalline Solids, Vol. 290, 2001, pp. 194-207.

7. H. Atmani and O. Thoumire, "Microstructure characterization of fluidized bed nitrided $\mathrm{Fe}-\mathrm{Si}$ and Fe-Si-Al foils", Bull. Mater. Sci., Vol. 25, No. 3, June 2002, pp. 219-225.

8. R. R. M. de Sousa, F. O. de Araújo, K. J. B. Ribeiro, M. W. D. Mendes, J. A. P. da Costa, C. Alves Jr., "Cathodic cage nitriding of samples with different dimensions", Material Science and Engineering A, Vol. 465, 2007, pp. 223-227.

9. C. Zhao, C.X. Li, H. Dong, T. Bell, "Study on the activate plasma nitriding and its nitriding mechanism", Sufrace \& Coatings Technology, Vol. 201, 2006, pp. 2320-2325.

10. Sh. Ahangarani, A.R. Sabour, F. Mahboubi, "Surface modification of 30CrNiMo8 low-alloy steel by active screen setup and conventional plasma nitriding methods", Applied Surface Science, Vol. 254, 2007, pp. 1427-1435.

11. S. Grognet, J.M. Le Breton, H. Atmani, J. Teillet, "Microstructural study of nanocrystalline $\mathrm{Fe}-(\mathrm{Cu}-\mathrm{Nb})-\mathrm{Si}-\mathrm{B}$ ribbons obtained by a nitriding thermochemical treatment", Journal of Magnetism and Magnetic Materials, Vol. 210, 2000, pp. 167-180.

12. F. Mahboubi, K. Abdolvahabi, "The effect of temperature on plasma nitriding behaviour of DIN 1.6959 low alloy steel”, Vacuum, Vol. 81, 2006, pp. 239-243.

13. O. Thoumire, H. Atmani, J. Teillet, E. Beucher, "Structural, mechanical and magnetic properties of nitrided FeSi and FeSiA1 sheets", Journal of Magnetism and Magnetic Materials, Vol. 196-197, 1999, pp. 346-348.

14. R.M. Bozorth, Ferromagnetism (Van Nostrand, Princeton, NJ, 1951), pp. 74-79.

15. S. Grognet, H. Atmani, R. Zuberek, K. Zellama, J. Teilet, "Structural, thermomagnetic and magnetostrictive properties of nanocrystallized Fe-Cu-(Nb)-Si-B-(N) ribbons", Journal of Alloys and Compounds, Vol. 282, 1999, pp. 236-242.

16. F.M. El-Hossary, N.Z. Negm, "Composition structure and magnetization of rf plasma nitrided 304 stainless steel”, Applied Surface Science, Vol. 181, 2001, pp. 185-190. 